\title{
Methodological Assumptions in the Scope of the Teaching of History
}

\author{
Nicola Maria Camerlengo \\ PhD student, Department of Prehistory and Antiquity Sciences, University of Salamanca, Salamanca, Spain.
}

\begin{abstract}
How to cite this paper: Nicola Maria Camerlengo. (2021). Methodological Assumptions in the Scope of the Teaching of History. The Educational Review, USA 5(3), 70-75.

DOI: 10.26855/er.2021.03.006
\end{abstract}

Received: February 4, 2021

Accepted: February 28, 2021

Published: March 29, 2021

Corresponding author: Nicola Maria Camerlengo, PhD student, Department of Prehistory and Antiquity Sciences, University of Salamanca, Salamanca, Spain.

Email: nmcamerlengo@gmail.com

\begin{abstract}
The exposition of the article in question focuses particularly on the problematic of the teacher relating first to the function of the transmission, then of learning, by the student, of the historical episode momentarily considered, no longer visualized and assumed in the "factum". In itself, as well as in the meaning expressed in it, which goes beyond the event itself, visualizing himself above all through moments of reflection, dialogue and criticism. Inside, we first contemplate the "schematic representation of the pedagogical encyclopedia" by A. Visalberghi, revisited on the occasion by the author, in a didactic historical key, with, in addition, the description of some educational processes contemplated within the methodological structure IHD by R. Cattell. Many projects can be adopted by the teacher: in this circumstance two will be underlined, attributed to Mazzotta M. and Professor Ferrone AM. Both scholars, pedagogues, while differentiating themselves in the different passages, aim to bring out the problematic nature of the topic taken under consideration, also historical in our circumstance, temporally structuring a series of situations that from the dialogue, even casual, between the emerging actors (teachers and students), gradually consolidate into several episodes, later concrete and causal, structured in different topics and nuances. At the laboratory level, numerous activities will be created, even unusual ones, rich in different objectives and particularities, in the proposal of new didactic "opportunities" various in the interdisciplinary composition.
\end{abstract}

\section{Keywords}

Historic Event, History Teaching, Method, Methodological Structure, Pedagogical Philosophy, Chronology, Periodization, Interdisciplinarity, Pluridisciplinarity

\section{Introduction}

The introductory proposal is identified at the beginning of the article itself. The author necessarily refers to the "schematic representation of the pedagogical encyclopedia" by A. Visalberghi, deepening the sector known as the "Content", now recognized in the historical didactic field which, as can be seen, goes beyond the episodic knowledge itself, in function, this time, of more moments of reflection and analysis contemplated in various educational procedural situations of an epistemological and multidisciplinary character, deepened within the meanings of chance and causality.

Finally, Mazzotta’s and Ferrone’s educational models will be described as a suggestion.

\section{Teacher training}

Each disciplinary field, as a segment of the great cultural container, to be transmitted from one subject to another (the 
first, it is assumed, indicated in the one who is already within the "knowledge", the second, instead, close to it, to discover and assimilate it) will have to describe itself through a set of channels and methods which, facilitating communication and the message, will specify the interaction between several actors, for example the teacher and the pupil, for the purpose of learning, determining an encounter serious between the psychic structure of the student and the other logic of the content.

Among the various study programmes in Italy, there is one, recently created, identified as the " 24 credits" among others, structured within a particular two-year Master, already consolidated and diversified into several disciplinary fields. No one can participate in any public competition, for teaching employment purposes, differentiated in various cultural paths, as previously mentioned, unless they attended (and passed) the course in question, held every two or three years by the Ministry of Education, conceived as qualifying for the job position as a professor.

Within the curriculum, several disciplines related to Pedagogy, Psychology and the methodological and didactic field are mandatory. Each student can access the qualifying course only after obtaining the specialist degree in the different disciplinary fields. I made my preparation, in this sense, following the method created by Anna Maria Ferrone, professor of General and Musical Pedagogy, Psychology of the Developmental Age, of methodology and teaching at the "G. Rossini" Music Conservatory of Pesaro and the Faculty of Education at the "G. D'Annunzio" University of Chieti-Pescara. I will therefore enter into the heart of the discussion, referring first to my university studies, then move on, in parallel, to the proposal of a hypothetical exploration of multiple psycho-pedagogical contents, to be intertwined within the Didactics of History.

First of all, in the qualifying courses, every future teacher, as we said, will have to verify and deepen more areas of study and research, already traced by the great scholar Aldo Visalberghi (Visalberghi, 1990), of which Prof. Ferrone also refer to. They are identified respectively:

a) in the sociological sector (sociology of small groups, general sociology, sociology of education and scholastic sociology, social and cultural anthropology, sociology of knowledge, economics and education policy)

b) in the psychological sector (social psychology, general psychology, developmental psychology, learning psychology, differential psychology, psychometrics and statistics)

c) in the methodological sector (docimology, special pedagogy, teaching methodologies, educational technologies, information technology and systems theory, logic)

d) in the content sector (diversified into several areas including mathematics, linguistics, history, science, religion, etc.)

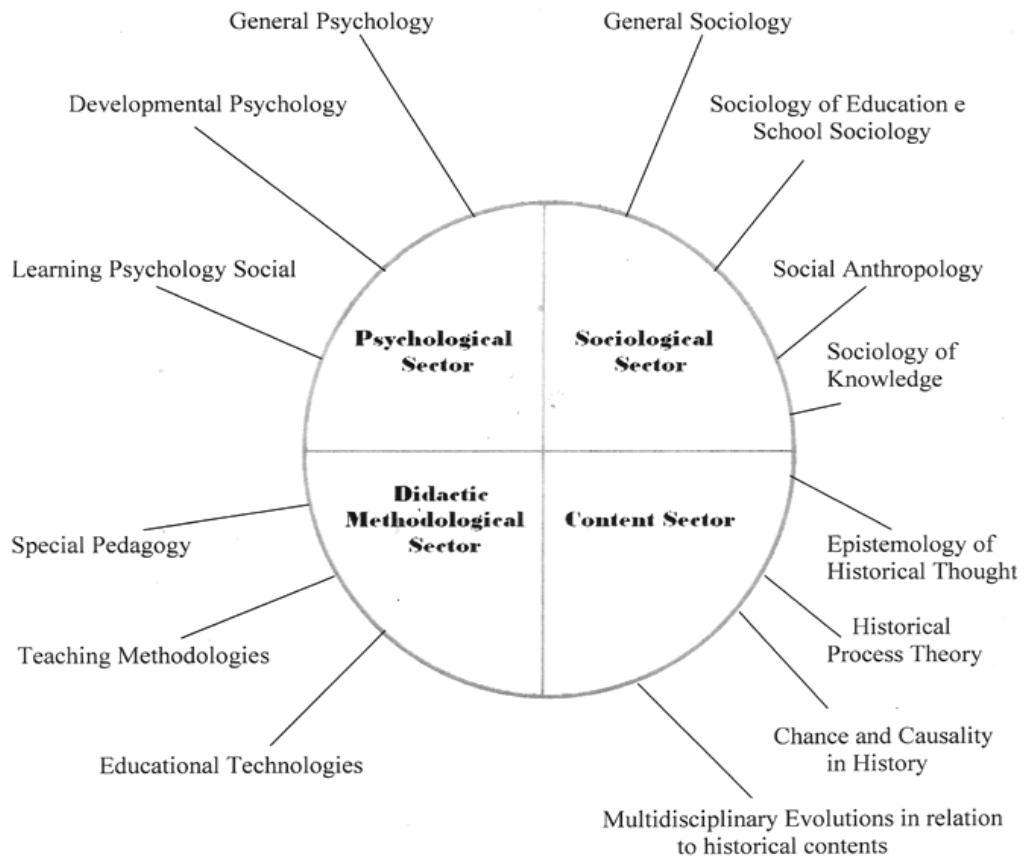

Figure 1. Schematic representation of the Pedagogical Encyclopedia of A. Visalberghi (revisited by the Author in a didactic historical key). 
The segments mentioned above represent the "nucleus" of the action, called transmission, contemplated as a whole in the area of scientific pedagogy which, precisely because of its wealth of "sub-fields", present in each sector, will be appropriately indicated, in the case of our research, in the "schematic representation of the pedagogical encyclopedia, revisited in a historical-didactic key".

The diatribe, often carried on by several experts in the sector, rightly claims not to exclude the knowledge, on the part of the teacher, of several contents or containers (Author's note) of the pedagogical action enriched, in the circumstance, by the conscious assumption of particular situations and historical topics in addition to others already absorbed by the student of the degree course, previously completed.

Part of these sectors, or areas, will compete with each other in determining a serious relationship between education and pedagogy: the first, as the object of the second, describes the actual pragmatic action, the other emphasizes the specific act of analysis and reflection.

\section{Pedagogical indications}

\section{$<<$ Pedagogy is to Reflection as Reflection is to Education $\quad P: R=R: E$}

consequently the educational pedagogical $R$ (reflection) constitutes the common element of both scientific realities now exposed:

$$
\boldsymbol{P} \longrightarrow \boldsymbol{R} \leftarrow \boldsymbol{E}
$$

Within these structures, the protagonists of the "scene", as we have just mentioned, are the teacher and the pupil. The main characters, learner and educator, determine the educational fact (the object of education) which is realized through an intense relationship in which with conscience and awareness, they realize their goals, their growth and maturity.

In the educational aspect emerges the research, the method, the will to take the best path, to consider and respect the physical and intellectual abilities of the individual and many other problems inherent and in any case always evident in the relationship in question. The difficulties and aspects just mentioned move and flow, or rather, they should flow within the pedagogical reality, in a continuous becoming and changing in which research and areas of realization are in concomitance with each other with the times, the places with the spaces, the ideas, the needs of the individual and of the group as a result of the society that man himself has created and determined in the course of history.

What is meant, therefore, by pedagogical reality, is not the determination of an abstract, fixed and universal code, but can be interpreted in the relationship, which has always existed, between man, understood in his entirety, materiality and spirituality, and his own and prospective historical evolution.

Reflection, self-awareness, the idea, the research, the ability to integrate and put oneself to test identify the resultant and the common point between the concept and the meaning we give to education and pedagogy. (Ferrone $\&$ De Felice, 2015) >>

\section{Method and methodological structure compared}

It is within this perspective that we believe to support those situations which, when teaching, introduce us to the methodological sphere. According to Prof. Ferrone's view, it is appropriate to distinguish the meaning of method and methodological structure. Of the latter there are, in principle, three models of which we recall the inductive (I), the deductive (D) and the inductive-deductive (I.H.D.). As stated, the first intends to describe the educational action through the exercise that from the detail will explain the general rule, the second is exactly the opposite of the first, that is, from theory to experiment. The latter is certainly the most complex since, in addition to the two phases just described, it incorporates a third, the hypothesis $(\mathrm{H})$ to be considered and proposed in the process in question towards an adolescent and adult audience. The latter model is attributed to R. Cattell and is inspired by the falsifiability principle of K. Popper (1970), the philosopher par excellence of twentieth-century science (Karl Popper, 1992).

In the process described above emerges the segment relating to the experiment which can be understood as a real experimentation: it can also be visualized and conceived within the laboratory, for example, which, according to Ferrone (2003a), should not be indicated as a place equipped for a particular activity, but as a way or manner of thinking, a mentality that can be placed in research.

\section{Didactic processes}

Regarding the method, we would say that it can be created simply by the teacher who moves according to the methodological structure that he deems, for his class, more appropriate, or he can adopt one already explained by more or less well-known pedagogues (remember Montessori, Pestalozzi, Herbart and even the most ancient and classic ones 
such as Comenius, Rousseau, Froebel, etc.). We like to insist, in particular, on Mazzotta's proposal (1982) divided into six moments to be distributed in succession over time. They are summarized as such:

1) in the presentation of stimuli

2) in the actual discussion of the class group expressed, at a later time, also through multiple simulations in which the students, as actors, relive the episode in progress, processing the various causes and situations inherent in it

3 ) in the teacher's presentation

4) in the moment of comparison and verification

5) in the reorganization of contents

6) in the formative test with self-correction of the students for collective feedback.

Going deeper into the topic as a final example, in this circumstance, the design of the Prof. Ferrone is made up of the following segments (Ferrone, 2003b):

a) discomfort of the researcher

b) interest of the researcher

c) formulation of the problem

d) methodological hypothesis of the path

e) data collection and retrieval

f) construction of the model

g) verification

The first is identified when the teacher/researcher autonomously questions himself on what to do, also experiencing moments of doubt and uncertainty while trying to configure, according to his/her skills and knowledge, the goal he/she intend to achieve. In the interest, the teacher involves other colleagues and experts in order to outline the teaching proposal through multiple tools also interdisciplinary, criticizing any sectoriality and ambiguity in the projection and production, instead of rich and possibly correct content frameworks. We will move on to the third segment in which the teacher will specify the ultimate goal that he/she intends to achieve by determining, in the research, the identification of teaching means and strategies necessary for its implementation. In the construction of the model, several macro-objectives will be illustrated to be contemplated in temporal succession, also investigated in micro, all determinants of the problem in question, to end, in the final verification, the project under consideration.

\section{The sensoriality and concreteness of the historical moment}

Let's talk now about design.

For elementary school, better indicated as primary, we will underline, as an example, the area close to us, to be illustrated in the formulation of the problem through two general objectives:

- to start the child to build his own cultural identity as an awareness of the reality in which he lives

- initiate the child to the construction of elementary attitudes and cognitive tools essential for the understanding of historical and social phenomena

Other segments, always to be noted in this first exhibition, insist on the knowledge and learning of the meaning of chronology, understood as an indispensable conventional tool for ordering and memorizing the events of the past, making the distinction of "before", "after" and "periodization". The contents of the general objectives just described, will clarify the pursuit of further contents expressed in micro objectives, also called specifics, summarized in:

- overcoming, by the child, of the perception of himself as a pivot and measure of reality in order to start feeling himself participating in a process that has roots and dimensions that go beyond him

- in the awareness that every judgment and every historical discourse identifies its foundation in the research and knowledge of the sources and in the methodological rigor

- in the gradual maturation of the awareness that the reconstruction of the historical fact is the result of a complex of technical and scientific operations progressing over time and activated by the cultural and civil interests of the researcher

The meaning of the story is identified first of all in that of the child: his physical being is the present. In ordering the day's actions, if indicated, the child will tend to hypothesize some that he will check the next day to confirm them, even with variables, with a new and near present (imminent future). He will deepen the existence of parents and possibly grandparents by placing them, (the latter), in a more distant past than his present. He will have to be involved in the action through the stimulation of its sensoriality: he will visualize the old and current "things", spatially giving them the right position. He will compare his family with others, who have long since settled in our country, through images, stories, toys, interviews, songs and nursery rhymes, etc.... fixing and valuing their differences and similarities. Billboards, films, simple monographs, stories with multiple illustrations, guided tours, such as educational trips, can be considered 
valid educational tools. While the student passes the period of childhood, approaching the subsequent adolescence to reach later the more mature one of adulthood in the perspective of the knowledge in question, he will re-examine the numerous topics and episodes, arranged over time, considering their most integral meanings of history itself understood as reality and legacy of the past which, in continuous reflection, enriched with multiple hypotheses, discoveries and knowledge, unravels and reorganizes through new scenarios, redetermining the collective memory of man steeped in old experiences and traditions, incident on the present , also displayed in the current globalization of facts.

During the qualifying courses, long periods of diversified didactic activity are foreseen with different age groups, indicated in the internship. The student, enrolled in it, is obliged to handle it with the co-presence of the teachers of the school structure, in which he is temporarily a guest, and the supervision of the university teacher in charge of the course in question. The participation of the same in the experiment occurs gradually: the trainee will first of all determine a second approach towards the members making up the class, helping and supporting them in the resolution of tasks, in learning and continuous exercise. In the action he will be able to follow procedural didactic models already applied and established or identify and create new ones that are valid at the moment and respond to the needs and demands of the class group. At the end, a report by the student will highlight the difficulties of the student in interacting and integrating with the class, also verifying what emerged as a positive contribution. After passing the course in question and the exams provided therein, the trainee student will be recognized as "qualified" for teaching to participate ipso facto in the competitions announced, over time, by the Ministry of Education.

To conclude, I would still like to insist on the question of the "meaning of sensoriality" contemplated in the historical episode that is discovered, known and learned from time to time.

First example many visitors, guests of some Italian museums, were asked a series of questions in which they, in answering, were able to interpret, naturally according to their point of view, the colors, for example, the lights, coming from inside or from the outside, the characters, their clothes, in reference to the historical time of belonging and geographical origin (more or less considered), the things, the setting, the shades in general, when present in the sculptures and paintings while they are displayed .

This aspect, also of a psychological nature, will be recorded by the restorer, in agreement with the art historian, when the same will revisit, as necessary, the work of art taken into consideration. Of course, the artist's message will be absolutely respected, but repositioned and deepened under different approaches and new angles.

Another example is remaining on the subject, we will highlight Leonardo da Vinci's "The Last Supper". As an experiment, some subjects more or less resembling the apostles and Jesus were sought out among the people. Taking a rectangular table, they were arranged and dressed in the same way as they appear in the mentioned fresco and similarly recreated the same setting. At the end of the experiment, both the public, gradually approximating there, and the protagonists themselves, divided into actors and directors, had the opportunity to dialogue with each other, highlighting and examining the scene in question, illustrating, in its complexity, the muscular sensations from the former, the intensity of the gaze, the tension felt and, probably because outdoors, the "sensorial" impact perceived in relation to the diversity of the places considered (one in Santa Maria delle Grazie in Milan, the other on the street).

This second activity, contemplated in the didactic practice of dramatization, carried out by several students, in this circumstance enrolled in a high school, will allow them to create an experience full of stimuli displayed in several areas, from the religious one, here par excellence, to the historical, artistic, pictorial, but also political, social, geographical, philosophical, musical, linguistic, etc. thus emphasizing the "interdisciplinary" element, which must never be neglected methodologically speaking. Another not insignificant segment is the opportunity to project the action, just described, outside a space that is usually unusual for students, accustomed to attending lessons in the classroom which, closed, is located inside a school building. The experiment may end in the consolidation of a detailed examination of the result produced, in which the class group, as director, will verify those situations which, positive and/or negative, will improve them in the future for the creation and implementation of new activities extrapolated from other socio-cultural areas or fields.

\section{References}

"However, I can recommend to any serious science student to look for a nice problem that he can really fall in love with and to which he is ready to dedicate his life. This attitude will make it easy for him to try and try again to find a solution, and to be critical of his own efforts which, in most cases, will have to be redoubled for them to be successful. And even if they appear to be successful, they should be questioned by himself, as they will usually be susceptible to improvement.” (Karl Popper, from a lecture given in 1992).

Author's note. Clearly, with reference to the historical content proposal, the future teacher will deepen, on the merits, those disciplines already indicated in the various study plans offered by universities. These institutions, for the first three sectors, will ex- 
trapolate some of them considered by them to be more interesting, therefore mandatory. The others, suggested by me and included in the "schematic representation of the pedagogical encyclopedia revisited in a historical-didactic key", are proposed here, very humbly, as a further moment of analysis and reflection.

Cattell, R. B. (n.d.). Psychological Theory and Scientific Method in handbook of Multivariate Experimental Psychology (pp. 10-17). edited by Cattell himself.

D.M. 616/2017 (2017). Ministry of Education.

Ferrone, A. M. (2003a). Dal metodo al progetto (From method to project), Percorsi didattici musicali ed integrazione scolastica in ambito musicoterapeutico (Musical educational paths and school integration in the music therapy field) (p. 51). Dienne edizioni.

Ferrone, A. M. (2003b). Percorso didattico pedagogico relativo all'educazione alla voce ed al canto (Educational pedagogical path relating to voice and singing education), Percorsi didattici musicali ed integrazione scolastica in ambito musicoterapeutico (Musical educational paths and school integration in the music therapy field). ( p. 52). Dienne edizioni.

Ferrone, A. M. and De Felice, F. (2015). L'approccio pedagogico (The pedagogical approach), La Musicoterapia tra didattica e didattica speciale in ambito sonoro musicale (Music therapy between teaching and special didactics in the musical sound field) (pp. 8-9). Dienne edition.

Honegger Fresco, G. (2018). Da solo io. Il progetto pedagogico di Maria Montessori da 0 a 3 anni (Alone me. The pedagogical project of Maria Montessori from 0 to 3 years). La meridian.

Honegger Fresco, G. (2020). I bambini e l'ambiente secondo il metodo Montessori (Children and the environment according to the Montessori method). Solferino.

Mazzotta, M. (1982). La programmazione (Programming). Bulgarini.

Popper, K. Logic of scientific discovery (first edition in English 1934, translated into Italian Logica della scoperta scientifica in 1970), (p. 22). Torino, Einaudi.

Visalberghi, A. (1990). La pedagogia diventa scientifica (Pedagogy becomes scientific) (p. 19), Pedagogia e scienze dell'educazione (Pedagogy and education sciences). Arnoldo Mondadori. 